\title{
EFFICIENT PORTFOLIOS VERSUS EFFICIENT MARKET
}

\section{James S. Ang*, Jess H. Chua**, and Anand S. Desai***}

One of the most important developments in modern investment theory is the efficient market hypothesis. Market efficiency refers to the speed with which information is rationally absorbed. Thus, statements about market efficiency are always made with respect to a particular set of information. Three information sets with respect to which the market may or may not be efficient have been defined, resulting in the weak, semi-strong, and strong form efficient market hypothesis. Weak form efficiency refers to efficiency with respect to past prices, semi-strong form to all publicly available information, and strong form to all available information, public or private. All three forms of the efficient market hypothesis have been tested by researchers. For an excellent review see Fama [5].

Only the weak-form hypothesis is of concern in this paper. The study compares the performance of the market portfolio with those of portfolios that are mean-beta efficient on the basis of historical means and betas. The tests are important because they have implications for both the multi-security weak-form efficient market hypothesis and the construction of efficient portfolios.

It is unfortunate that the word "efficient" is used to convey very different concepts in portfolio theory and the efficient market hypothesis. What is even more ironic is that the two concepts are actually contradictory. If the market is truly efficient, it does not matter if efficient portfolios are derived with historical return and risk measures, historical measures adjusted for other publicly or privately available information, or completely subjective measures. The efficient portfolios cannot be expected to consistently earn returns superior to that yielded by the market portfolio. On the other hand, if any of these portfolios can earn consistently superior returns, then the market cannot be efficient.

Although this paradox has not been addressed directly before, studies by Cohen and Pogue [3] and Frankfurter [8] do contain some relevant results. Cohen and Pogue found that efficient portfolios outperformed random portfolios of 50 securities. Frankfurter, on the other hand, found efficient portfolios to perform only as well as the market portfolio. Since Evans and Archer [4] have shown that random porfolios of the size used by Cohen and Pogue are essentially equivalent to the market portfolio, the two sets of results are contradictory.

A problem with the results is that the tests were both conducted on a very limited number of securities and for only one time period. For example, although Frankfurter utilized a sample of 522 stocks to construct his efficient portfolios, he selected only one portfolio for comparison with the market portfolio, the portfolio being one with the risk equal to that of the market portfolio. When the efficient portfolio was found to be insignificantly different from the market portfolio, the conclusion was drawn that the efficient portfolios only perform as well as the market portfolio. It should be remembered, of course, that the main purpose of

* Florida State University

**The University of Calgary

***The University of Michigan 
Frankfurter's paper was not to test the performance of efficient portfolios $v i s-a$-vis the market portfolio.

If one discounts Frankfurter's results and looks only at Cohen and Pogue's results, he would then have to conclude that the market may actually not be multisecurity weak-form efficient. Obviously, only an examination with a more extensive sample of securities and covering more than one time period can resolve the issue.

As pointed out by Fama [5], weak-form tests have been mainly concerned with information in single securities. Accordingly, inferences about market efficiency can be made only with regard to the set of information contained in past prices of securities taken one at a time. No conclusion can be drawn with respect to the set of securities taken all at once. This study tests the weak-form hypothesis with an information set containing historical means and betas. Since only historical returns are used to generate the means and betas, it is a weak-form test. Since the beta of a particular security is based on the historical relationship between the security and all others in the market, multi-security information is used. Thus, this study may be seen as an addition to the very lean literature on multi-security market efficiency.

In Section I the empirical methodology is explained. Results are presented and interpreted in Section II. Conclusions are made in Section III.

\section{Empirical Methodology}

The procedure consisted of three steps. First, Sharpe efficient portfolios were constructed from the universe of NYSE stocks using data from several time periods designated as construction periods. Second, the returns, means, betas of these efficient portfolios were computed in the evaluation period. Third, performances were evaluated against the market portfolio.

\section{Step 1: Construction of Efficient Portfolios}

The basic data for the study were the dividend adjusted monthly security return series of the CRSP (Center for Research in Security Prices, University of Chicago) tape and the CRSP market value weighted index (see Fisher [7]). The period covered in this study was January, 1926 to December, 1965. This corresponds to the period used by Black, Jensen and Scholes [2] (BJS, hereafter). The interval was divided into 21 subperiods consisting of the first 60 months, three 105 -month subperiods, and seventeen 24-month subperiods. The return observations from each of these subperiods were used to generate efficient portfolios for each of the construction periods. All stocks with complete data for each construction period were included in the population for that particular period. These stocks were considered even if they did not have complete data for the subsequent evaluation period, thus avoiding a source of selection bias and imitating feasible investor behavior.

Using the Sharpe [15] model, a total of 1,395 portfolios was generated for the 21 subperiods. The compositions of the efficient portfolios were, thus, obtained in this step.

\section{Step 2: Computation of Returns in the Evaluation Periods}

For each of the portfolios generated, the returns for the evaluation periods were calculated. The evaluation periods were those immediately following the construc- 
tion periods and of the same duration. These evaluation periods corresponded to those used by $B J S$ in testing the security market line.

The actual monthly returns of each portfolio were computed as:

$$
\left(R_{p}\right)_{k t}=\sum_{j=1}^{N_{k}} x_{k j} R_{j t} \quad t=1, \ldots, T ; k=1, \ldots, 1395
$$

where: $\quad\left(R_{p}\right)_{k t}=$ return on portfolio $k$ for time $\left.t(k=1), \ldots, 1395\right)$;

$x_{k j}=$ proportion of portfolio $k$ that consists of stock $j$;

$R_{j t}=$ return on stock $j$ for time $t$;

$N_{k}=$ number of securities in portfolio $k$ (varies from 38 to 75 );

$T=$ number of months in the evaluation period (105 months or 24 months)

The mean returns $\left(\bar{R}_{p}\right)_{k}$ and the betas $B_{p k}$ of these portfolios were then calculated, respectively, as follows:

$$
\begin{aligned}
& \left(\bar{R}_{p}\right)_{k}=\underbrace{T}_{t=1}\left(1+\left(R_{p}\right)_{k t}\right] 1 / T_{-1.0} k=1, \ldots, 1395 \\
& \left.B_{p k}=\sum_{t=1}^{T}\left[\left(R_{p}\right)_{k t}-\left(\bar{R}_{p}\right)_{m}\right]\left[R_{m t}-\vec{R}_{m}\right] / \sum_{t=1}^{T}\left(R_{m t}-\bar{R}_{m}\right)^{2}\right] .
\end{aligned}
$$

\section{Step 3: Performance Evaluation}

There are three commonly used performance measures: the Sharpe, Treynor and Jensen indexes, all derived from the original Capital Asset Pricing Model. Conceptually, the Treynor and Jensen indexes are superior because only the systematic risk is considered relevant, and most investments contain unsystematic risk. These two indexes are basically the same in that if a portfolio's performance is judged superior (inferior) to the market portfolio by the former index, it will be judged the same by the latter.

Deficiencies have been found in the original Capital Asset Pricing Model; therefore, modifications have been necessary. The most popularly accepted modification is substituting the risk-free rate with the return of the minimum variance zero beta portfolio as proposed by Black [1] and tested by BJS. Obviously, the performance indexes also have to be modified. Unfortunately, returns on the minimum variance zero beta portfolio are not directly and independently observable. Only the average is implied in the intercept of the two-parameter security market line. Therefore, as suggested by Fama [6], the most convenient way of accommodating this modification is to use empirically-derived two-parameter security market lines directly. When the security market lines are used directly, any portfolio whose mean-beta combination plots above (below) the line is superior (inferior) to the market portfolio. Directly using the empirically-obtained security market line to represent the market portfolio has the additional advantage that confidence intervals can be drawn around the market line, thus permitting statistical inference. 
The reader familiar with weak-form efficient market tests will note that the correct comparison in a fair-game test should be between the test portfolios and the buy-and-hold strategy. In this particular study the CRSP market portfolio is indeed the buy-and-hold strategy since the opportunity set considered consisted of all the stocks in the CRSP tape.

The two-parameter security market lines used here are those obtained by BJS. Confidence intervals equal to two times the reported standard errors of intercepts were constructed. The confidence intervals should have been based on the standard errors of regressions; however, this was not reported by $B J S$. Using the standard error of the intercept understates the width of the confidence interval and biases the results in favor of rejecting the efficiency hypothesis. Therefore, this inaccuracy does not cause problems if the evidence obtained does not reject the hypothesis. Performance evaluation consisted of plotting the mean-beta combinations of the test portfolios onto the security market line of the evaluation period.

Roll $[13,14]$ has shown that if the market proxy is ex post mean variance efficient, then no superior or inferior performance can be found by the security market line. If superior performance is found, however, it is always possible to find another market proxy that will indicate inferior performance. In effect, Roll has shown that performance evaluations based on the security market line are ambiguous. Mayers and Rice [11] have salvaged the use of the security market line for performance evaluation somewhat by arguing that, empirically, the market proxy is unlikely to be ex post mean-variance efficient. Theoretically, they argue that if the security market line depicts the experience of uninformed investors, and a particular investment consistently plots above the market line, then there is relative, if not absolute, superiority. However, they have no answer to the question of highly correlated market proxies that could indicate contradictory evaluations. Therefore, there are still problems with $C A P M$-based performance evaluations.

To circumvent the ambiguity problem, the second-degree stochastic dominance (SSD) framework (Hadar and Russell [9], Hanoch and Levy [10]) was used to compare the performances of the test portfolios with that of the market portfolio as represented by the $C R S P$ value-weighted index. Theoretically, this is not as proper a test as the one with the $C A P M$. First, mean-variance efficiency is not equivalent to stochastic dominance efficiency. Since the information set used contains only the first two moments, it is unfair to require the portfolios based on it to perform better than the market portfolio when all moments are taken into account. To this objection we have recourse only to expediency for defense. Second, in the stochastic dominance framework, the market portfolio does not dominate other portfolios. To this objection, precedence in many studies of performances of mutual funds can be noted (e.g. [12]). In fact, there is a better reason for using the market portfolio since it is the buy-and-hold alternative.

For an illustration of the procedure, refer to Table 1 . The first sample used return observations from the construction period (1/1926-12/1930) to obtain the compositions of 49 efficient portfolios. Then the returns, means, and betas of these portfolios were calculated for the evaluation period $(1 / 1931-9 / 1939)$. The mean-beta combinations calculated were then plotted on the security market line obtained by $B J S$ for the period (1/1931-9/1939). When a portfolio was above (below) the line and outside the confidence interval, it was designated a superior (inferior) portfolio; 
TABLE 1. STEP I - Efficient Portfolio Generation

\begin{tabular}{ccccc}
\hline $\begin{array}{c}\text { Sample } \\
\text { No. }\end{array}$ & $\begin{array}{c}\text { Construction } \\
\text { Period }\end{array}$ & $\begin{array}{c}\text { Evaluation } \\
\text { Period }\end{array}$ & $\begin{array}{c}\text { Size of } \\
\text { Candidate } \\
\text { List }\end{array}$ & $\begin{array}{c}\text { No. of } \\
\text { Efficient } \\
\text { Portfolios }\end{array}$ \\
\hline 1 & $11 / 1926-12 / 1930$ & $1 / 1931-9 / 1939$ & 375 & 49 \\
2 & $1 / 1931-9 / 1939$ & $10 / 1939-6 / 1948$ & 545 & 44 \\
3 & $10 / 1939-6 / 1948$ & $7 / 1948-3 / 1957$ & 710 & 75 \\
4 & $7 / 1948-3 / 1957$ & $4 / 1957-12 / 1965$ & 860 & 75 \\
& & & & 38 \\
5 & $1 / 1930-12 / 1931$ & $1 / 1932-12 / 1933$ & 625 & 62 \\
6 & $1 / 1932-12 / 1933$ & $1 / 1934-12 / 1935$ & 650 & 75 \\
7 & $1 / 1934-12 / 1935$ & $1 / 1936-12 / 1937$ & 660 & 55 \\
8 & $1 / 1936-12 / 1937$ & $1 / 1938-12 / 1939$ & 680 & 44 \\
9 & $1 / 1938-12 / 1939$ & $1 / 1940-12 / 1941$ & 735 & 54 \\
10 & $1 / 1940-12 / 1941$ & $1 / 1942-12 / 1943$ & 760 & 75 \\
11 & $1 / 1942-12 / 1943$ & $1 / 1944-12 / 1945$ & 780 & 75 \\
12 & $1 / 1944-12 / 1945$ & $1 / 1946-12 / 1947$ & 790 & 75 \\
13 & $1 / 1946-12 / 1947$ & $1 / 1978-12 / 1949$ & 840 & 74 \\
14 & $1 / 1948-12 / 1949$ & $1 / 1950-12 / 1951$ & 930 & 75 \\
15 & $1 / 1950-12 / 1951$ & $1 / 1952-12 / 1953$ & 970 & 75 \\
16 & $1 / 1952-12 / 1953$ & $1 / 1954-12 / 1955$ & 1,000 & 75 \\
17 & $1 / 1954-12 / 1955$ & $1 / 1956-12 / 1957$ & 1,000 & 75 \\
18 & $1 / 1956-12 / 1957$ & $1 / 1958-12 / 1959$ & 1,000 & 75 \\
19 & $1 / 1958-12 / 1959$ & $1 / 1960-12 / 1961$ & 1,025 & 1,025 \\
20 & $1 / 1960-12 / 1961$ & $1 / 1962-12 / 1963$ & 1,065 & \\
21 & $1 / 1962-12 / 1963$ & $1 / 1964-12 / 1965$ & & 75 \\
\hline
\end{tabular}

otherwise its performance was deemed equal to that of the market. The stochastic dominance evaluations also used exactly the same time period partitions.

\section{Results and Analysis}

Table 1 shows the 21 subperiods for which efficient portfolios were constructed and evaluated. The opportunity set for each subperiod consisted of those stocks with complete monthly return data during the construction periods. Data availability on the CRSP tape during the construction period was thus the only criterion for a security to be a member of the opportunity set. The opportunity set increased in the more recent years since complete return data were available for a greater number of securities in these years than in the 30's and early 40 's.

The first sample had a construction period of 60 months and an evaluation period of 105 months. The second, third, and fourth samples had both construction and evaluation periods of 105 months. Samples 5 to 21 had construction and evaluation periods of 24 months. As stated previously, the subperiods were chosen to make the evaluation periods coincide with the subperiods used by $B J S$ in constructing their market lines.

The portfolio generating algorithm was designed to produce a maximum of 75 efficient portfolios. The maximum was chosen after the observation that when more than 75 efficient portfolios were constructed, many of the portfolios were redundant in that their compositions were almost the same. For certain samples (specifically 1 , 
TABLE 2. Comparison of Portfolio Performance with BJS Lines

\begin{tabular}{|c|c|c|c|c|c|}
\hline \multirow[b]{2}{*}{$\begin{array}{c}\text { Sample } \\
\text { No. }\end{array}$} & \multirow[b]{2}{*}{$\begin{array}{c}\text { Total No. } \\
\text { of } \\
\text { Portfolios }\end{array}$} & \multicolumn{2}{|c|}{$\begin{array}{l}\text { No. of Portfolios } \\
\text { Above BJS Lines }\end{array}$} & \multicolumn{2}{|c|}{$\begin{array}{l}\text { No. of Portfolios } \\
\text { Below BJS Lines }\end{array}$} \\
\hline & & $\begin{array}{c}\text { Within } \\
\text { 1SD } \\
\text { Bond }\end{array}$ & $\begin{array}{c}\text { Outside } \\
\text { 1SD } \\
\text { Bond }\end{array}$ & $\begin{array}{c}\text { Within } \\
\text { 1SD } \\
\text { Bond }\end{array}$ & $\begin{array}{c}\text { Outside } \\
\text { 1SD } \\
\text { Bond } \\
\end{array}$ \\
\hline 1 & 49 & 0 & 0 & 49 & 0 \\
\hline 2 & 44 & 0 & 0 & 44 & 0 \\
\hline 3 & 75 & 0 & 0 & 75 & 0 \\
\hline 4 & 75 & 0 & 0 & 75 & 0 \\
\hline 5 & 38 & 27 & 0 & 11 & 0 \\
\hline 6 & 62 & 1 & 0 & 11 & 0 \\
\hline 7 & 75 & 31 & 0 & 44 & 0 \\
\hline 8 & 55 & 48 & 0 & 7 & 0 \\
\hline 9 & 44 & 5 & 0 & 39 & 0 \\
\hline 10 & 54 & 22 & 0 & 32 & 0 \\
\hline 11 & 75 & 34 & 0 & 41 & 0 \\
\hline 12 & 75 & 0 & 0 & 75 & 0 \\
\hline 13 & 75 & 2 & 0 & 73 & 0 \\
\hline 14 & 74 & 0 & 0 & 74 & 0 \\
\hline 15 & 75 & 60 & 0 & 15 & 0 \\
\hline 16 & 75 & 29 & 0 & 46 & 0 \\
\hline 17 & 75 & 17 & 0 & 58 & 0 \\
\hline 18 & 75 & 75 & 0 & 0 & 0 \\
\hline 19 & 75 & 75 & 0 & 0 & 0 \\
\hline 20 & 75 & 0 & 0 & 74 & 1 \\
\hline 21 & 75 & 65 & 0 & 10 & 0 \\
\hline TOTAL & 1,395 & 491 & 0 & 903 & 1 \\
\hline
\end{tabular}

$2,5,6,8,9,10$, and 14 in Table 1), less than 75 efficient portfolios were obtained because of the interval used in partitioning the range of returns and betas.

\section{A. Performance Evaluation With the BJS Lines}

Table 1 shows the results of performance evaluation against the $B J S$ lines. Of the 1,395 portfolios compared, 1,394 lay within one standard error from the BJS lines. One was outside the one standard error interval, but well within the two standard error interval. Thus, the results overwhelmingly show that the efficient portfolios performed ony as well as the market portfolios.

If the confidence intervals around the $B J S$ lines are neglected, the results show that almost twice as many portfolios lay below the $B J S$ lines as above ( 905 versus 491) implying that utilizing the information set does not result in superior performances, at least not on any consistent basis. In addition, it was found that portfolios which were above the market lines could not be identified a priori on the basis of means or betas. Therefore, there is no way for one to invest only in the "superior" efficient portfolios. If one invests in all the efficient portfolios, then two-thirds of the investment will underperform the market and only one-third will outperform the market. 
TABLE 3. Comparison of Portfolio Performance: Stochastic Dominance Test

\begin{tabular}{|c|c|c|c|c|c|}
\hline \multirow[b]{2}{*}{$\begin{array}{c}\text { Sample } \\
\text { No. } \\
\end{array}$} & \multirow[b]{2}{*}{$\begin{array}{c}\text { Performance } \\
\text { Evaluation } \\
\text { Period }\end{array}$} & \multirow[b]{2}{*}{$\begin{array}{c}\text { Total No. } \\
\text { of } \\
\text { Portfolios }\end{array}$} & \multicolumn{3}{|c|}{ STOCHASTIC DOMINANCE TEST } \\
\hline & & & $\begin{array}{c}\text { Portfolio } \\
> \\
\text { Market }\end{array}$ & $\begin{array}{c}\text { Portfolio } \\
= \\
\text { Market }\end{array}$ & $\begin{array}{c}\text { Portfolio } \\
< \\
\text { Market }\end{array}$ \\
\hline 1 & $1 / 31-9 / 39$ & 49 & 24 & 20 & 5 \\
\hline 2 & $10 / 39-6 / 48$ & 44 & 16 & 12 & 16 \\
\hline 3 & $7 / 48-3 / 57$ & 75 & 61 & 13 & 1 \\
\hline 4 & $4 / 57-12 / 65$ & 75 & 0 & 3 & 72 \\
\hline 5 & $1 / 32-12 / 33$ & 38 & 30 & 8 & 0 \\
\hline 6 & $1 / 34-12 / 35$ & 62 & 24 & 15 & 23 \\
\hline 7 & $1 / 36-12 / 37$ & 75 & 8 & 0 & 67 \\
\hline 8 & $1 / 38-12 / 39$ & 55 & 44 & 5 & 6 \\
\hline 9 & $1 / 40-12 / 41$ & 44 & 25 & 5 & 14 \\
\hline 10 & $1 / 42-12 / 43$ & 54 & 47 & 0 & 7 \\
\hline 11 & $1 / 44-12 / 45$ & 75 & 75 & 0 & 0 \\
\hline 12 & $1 / 46-12 / 47$ & 75 & 0 & 0 & 75 \\
\hline 13 & $1 / 48-12 / 49$ & 75 & 75 & 0 & 0 \\
\hline 14 & $1 / 50 \cdot 12 / 51$ & 74 & 0 & 0 & 74 \\
\hline 15 & $1 / 52-12 / 53$ & 75 & $\mathbf{0}$ & 5 & 70 \\
\hline 16 & $1 / 54-12 / 55$ & 75 & 0 & 0 & 75 \\
\hline 17 & $1 / 56-12 / 57$ & 75 & 0 & 7 & 68 \\
\hline 18 & $1 / 58-12 / 59$ & 75 & 63 & 7 & 5 \\
\hline 19 & $1 / 60-12 / 61$ & 75 & 66 & 9 & 0 \\
\hline 20 & $1 / 62-12 / 63$ & 75 & 0 & 0 & 75 \\
\hline 21 & $1 / 64-12 / 65$ & 75 & 75 & 0 & 0 \\
\hline TOTAL & & 1,395 & 633 & 109 & 653 \\
\hline
\end{tabular}

Again, if the statistical insignificance of the "superior" and "inferior" performances is neglected, the results would show that in each one of the four 105 -month subperiods the efficient portfolios underperformed the market. For the 24-month subperiods greater than half the efficient portfolios outperformed the market in only six out of seventeen subperiods. This is no evidence to prove any superiority of the efficient portfolios. Furthermore, the fact that 24-month evaluations showed better results than the 105-month evaluations could indicate the transiency of even the statistically insignificant "superiority." Since, by the present criterion, the efficient portfolios clearly did not outperform the market portfolio, it was found unnecessary to evaluate the performances of the portfolios in subperiods following the evaluation periods.

\section{B. Performance Evaluation With the SSD Framework}

Table 3 shows the results when the performances of the 1,395 efficient portfolios were evaluated against the $C R S P$ value-weighted index used as a proxy of the market portfolio. The evaluation periods used for the previous tests were also used here.

Overall, the results agree with the $C A P M$-based tests. The performances of efficient portfolios $v i s-a$-vis the market portfolio question the usefulness of the infor- 
TABLE 4. Comparison of Portfolio Performance: Stochastic Dominance Test Second Evaluation Period

\begin{tabular}{|c|c|c|c|c|c|}
\hline \multirow[b]{2}{*}{$\begin{array}{c}\text { Sample } \\
\text { No. } \\
\end{array}$} & \multirow[b]{2}{*}{$\begin{array}{c}\text { Performance } \\
\text { Evaluation } \\
\text { Period } \\
\end{array}$} & \multirow[b]{2}{*}{$\begin{array}{c}\text { Total No. } \\
\text { of } \\
\text { Portfolios }\end{array}$} & \multicolumn{3}{|c|}{ STOCHASTIC DOMINANCE TEST } \\
\hline & & & $\begin{array}{c}\text { Portfolio } \\
> \\
\text { Market }\end{array}$ & $\begin{array}{c}\text { Portfolio } \\
= \\
\text { Market }\end{array}$ & $\begin{array}{c}\text { Portfolio } \\
< \\
\text { Market }\end{array}$ \\
\hline 1 & $10 / 39-6 / 48$ & 49 & 8 & 19 & 22 \\
\hline 2 & $7 / 48-3 / 57$ & 44 & 0 & 12 & 32 \\
\hline 3 & $4 / 57-12 / 65$ & 75 & 69 & 1 & 5 \\
\hline 4 & $4 / 66-9 / 74$ & 75 & 47 & 6 & 22 \\
\hline 5 & $1 / 34-12 / 35$ & 38 & 34 & 0 & 4 \\
\hline 6 & $1 / 36-12 / 37$ & 62 & 44 & 12 & 6 \\
\hline 7 & $1 / 38-12 / 39$ & 75 & 5 & 61 & 9 \\
\hline 8 & $1 / 40-12 / 41$ & 55 & 44 & 2 & 9 \\
\hline 9 & $1 / 42-12 / 43$ & 44 & 1 & 0 & 43 \\
\hline 10 & $1 / 44-12 / 45$ & 54 & 26 & 3 & 25 \\
\hline 11 & $1 / 46-12 / 47$ & 75 & 0 & 1 & 74 \\
\hline 12 & $1 / 52-12 / 53$ & 74 & 1 & 5 & 26 \\
\hline 13 & $1 / 50-12 / 51$ & 75 & 0 & 1 & 74 \\
\hline 14 & $1 / 52-12 / 53$ & 74 & 1 & 1 & 72 \\
\hline 15 & $1 / 54-12 / 55$ & 75 & 53 & 2 & 20 \\
\hline 16 & $1 / 56-12 / 57$ & 75 & 75 & 0 & 0 \\
\hline 17 & $1 / 58-12 / 59$ & 75 & 53 & 0 & 22 \\
\hline 18 & $1 / 60-12 / 61$ & 75 & 73 & 0 & 2 \\
\hline 19 & $1 / 62-12 / 63$ & 75 & 0 & 0 & 75 \\
\hline 20 & $1 / 64-12 / 65$ & 75 & 45 & 9 & 21 \\
\hline 21 & $1 / 66-12 / 67$ & 75 & 15 & 3 & 57 \\
\hline TOTAL & & 1,395 & 637 & 138 & 620 \\
\hline
\end{tabular}

mation set in attaining performances consistently superior to that of the market portfolio.

Of the 1,395 efficient portfolios tested, 633 were found by the SSD framework to perform better than the market, 109 to perform as well as the market, and 653 to perform worse. Therefore, slightly less than half $(\mathbf{4 3 . 3 \% )}$ ) outperformed the market portfolio in their respective periods. Such a division of number between superior and inferior performance is well within the range of errors when comparing random samples with equivalent properties. If the evaluation periods within which more than half the efficient portfolios outperformed the market are counted, the results are similar. One (sample No. 3) of four 105-month periods and nine (sample Nos. 5 , $8,9,10,11,13,18,19$, and 21 ) of seventeen 24 -month periods showed this tendency. The presence of the 633 "superior" portfolios must be further discounted because there is no test for the statistical significance of the superiority. Further, there is no way of identifying a priori the portfolios that would outperform or underperform the market portfolio either through the means or the betas.

To examine these portfolios further, their performances in respective secondevaluation periods were compared with the corresponding market returns. If, again, about half seem to outperform the market and the other half seem to underperform, 
TABLE 5 Comparison of Portfolio Performance: Stochastic Dominance Test Both Periods

\begin{tabular}{|c|c|c|c|c|c|}
\hline \multirow[b]{2}{*}{$\begin{array}{c}\text { Data } \\
\text { Set } \\
\text { No. }\end{array}$} & \multirow[b]{2}{*}{$\begin{array}{c}\text { Consolidation } \\
\text { Period }\end{array}$} & \multirow[b]{2}{*}{$\begin{array}{c}\text { Total No. } \\
\text { of } \\
\text { Portfolios }\end{array}$} & \multicolumn{3}{|c|}{ STOCHASTIC DOMINANCE TEST } \\
\hline & & & $\begin{array}{c}\text { Portfolio } \\
> \\
\text { Market }\end{array}$ & $\begin{array}{c}\text { Portfolio } \\
= \\
\text { Market }\end{array}$ & $\begin{array}{c}\text { Portfolio } \\
< \\
\text { Market }\end{array}$ \\
\hline 1 & $1 / 31-6 / 48$ & 49 & 2 & 47 & 0 \\
\hline 2 & $10 / 39-3 / 57$ & 44 & 0 & 32 & 12 \\
\hline 3 & $7 / 49-12 / 65$ & 75 & 55 & 20 & 0 \\
\hline 4 & $4 / 57-9 / 74$ & 75 & 0 & 55 & 20 \\
\hline 5 & $1 / 32-12 / 35$ & 38 & 26 & 12 & 0 \\
\hline 6 & $1 / 34-12 / 37$ & 62 & 24 & 38 & 0 \\
\hline 7 & $1 / 36-12 / 39$ & 75 & 0 & 74 & 1 \\
\hline 8 & $1 / 38-12 / 41$ & 55 & 42 & 7 & 6 \\
\hline 9 & $1 / 40-12 / 43$ & 44 & 1 & 29 & 14 \\
\hline 10 & $1 / 42-12 / 45$ & 54 & 26 & 21 & 7 \\
\hline 11 & $1 / 44 \cdot 12 / 47$ & 75 & 0 & 75 & 0 \\
\hline 12 & $1 / 46 \cdot 12 / 49$ & 75 & 0 & 50 & 25 \\
\hline 13 & $1 / 48-12 / 51$ & 75 & 0 & 75 & 0 \\
\hline 14 & $1 / 50-12 / 53$ & 74 & 0 & 2 & 72 \\
\hline 15 & $1 / 52-12 / 55$ & 75 & 0 & 56 & 19 \\
\hline 16 & $1 / 54-12 / 57$ & 75 & 0 & 75 & 0 \\
\hline 17 & $1 / 56-12 / 59$ & 75 & 0 & 60 & 15 \\
\hline 18 & $1 / 58-12 / 61$ & 75 & 63 & 12 & 0 \\
\hline 19 & $1 / 60-12 / 63$ & 75 & 0 & 75 & 0 \\
\hline 20 & $1 / 62-12 / 65$ & 75 & 0 & 54 & 21 \\
\hline 21 & $1 / 64-12 / 67$ & 75 & 15 & 60 & $\mathbf{0}$ \\
\hline TOTAL & & 1,395 & 254 & 929 & 212 \\
\hline
\end{tabular}

the belief that efficient portfolios do not dominate the market portfolio would be strengthened. Table 4 shows the results. Again, nearly as many portfolios outperformed as underperformed (637 versus 620 ).

Table 5 shows how many of the portfolios consistently outperformed the market over the first-and second-evaluation periods. The classification was as follows: if a portfolio outperformed the market in both evaluation periods or if it outperformed in one and was equal in another, it was considered a superior portfolio; vice-versa for inferior portfolios. When a portfolio changed from superior to inferior, or viceversa, or was equal in both periods to the market portfolio, it was considered equal to the market.

The results show that only 254 of the 1,395 portfolios outperformed the market consistently, while 212 portfolios were consistently inferior. Only three of the seventeen 24-month samples had more than half the portfolios consistently outperforming the market portfolio. Thus, if an investor had used the results of the first evaluation period as a guide and had invested in the 633 portfolios which outperformed the market in that period, 254 would have been indeed superior, but 379 would have been inferior.

Another strategy that an investor could have followed was to have invested in the superior portfolios only when a majority of the efficient portfolios outperformed 
the market. This strategy would have worked with one of the three 105-month samples. Of the 61 superior portfolios in sample No. 3, 55 remained superior in the subsequent subperiod. However, when the 24-month samples are examined, only in four (Nos. 5, 8, 10, and 18) of the nine subperiods would an investor have outperformed the market. In the others he would have fared worse than the market.

One may, therefore, conclude that the evidence from using the $S S D$ framework supports the evidence from the previous tests using the BJS lines. The paradox between the efficient market hypothesis and efficient portfolios based on historical means and betas should be resolved in favor of the efficient market hypothesis.

\section{III.Summary and Conclusions}

This study provides the results of two extensive tests to resolve the paradox that a multi-security efficient market may make futile efforts to construct efficient portfolios other than the market portfolio. 1,395 efficient portfolios for 21 subperiods from January, 1926 to December, 1965 were constructed. These portfolios were not found to outperform or underperform the market represented by the Black-JensenScholes market lines. The second-degree stochastic dominance tests also indicated no consistently superior performance by these efficient portfolios. The results, in effect, show that the market has already used the information set incorporated in this study in its pricing of securities. Therefore, one may conclude that the evidence does not reject the multi-security weak-form efficient market hypothesis.

\section{REFERENCES}

1. F. Black, "Capital Market Equilibrium with Restricted Borrowing," Journal of Business (July 1972), 444-454.

2. F. Black, M.C. Jensen, and M. Scholes, "The Capital Asset Pricing Model: Some Empirical Tests," in M.C. Jensen (ed.) Studies in the Theory of Capital Markets (New York, Praeger), 1972, 79-121.

3. K.J. Cohen, and J.A. Pogue, "An Empirical Evaluation of Alternative Portfolio Selection Models," Journal of Business (April 1967), 166-193.

4. J.H. Evans and S.H. Archer, "Diversification and the Reduction of Dispersion: An Empirical Analysis," Journal of Finance (December 1968), 761-767.

5. E.F. Fama, 'Efficient Capital Markets: A Review of Theory and Empirical Work," Journal of Finance (May 1970), 383-417.

6. E.F. Fama, "Components of Investment Performance," Journal of Finance (June, 1972), 551-568.

7. L. Fisher, “Some New Stock Market Indexes," Journal of Business (January 1966), 191-225.

8. G.M. Frankfurter, "The Effect of 'Market Indexes' on the Ex Post Performance of the Sharpe Portfolio Selection Model," Journal of Finance (June 1976), 949-955.

9. J. Hadar and W. Russell, "Rules for Ordering Uncertain Prospects," American Economic Review (March 1969), 25-34.

10. G. Hanoch and H. Levy, "The Efficiency Analysis of Choices Involving Risk," Review of Economic Studies (July 1969), 335-346.

11. D. Mayers and E.M. Rice, "Measuring Portfolio Performance and the Empirical Content of Asset Pricing Models," Journal of Financial Economics (May 1979), 3-28.

12. J. Meyer, "Further Applications of Stochastic Dominance to Mutual Fund Performance," Journal of Financial and Quantitative Analysis (June 1977), 235-242.

13. R. Roll, "A Critique of the Asset Pricing Theory's Tests," Journal of Financial Economics (March 1977), 129-176. 
14. R. Roll, "Ambiguity When Performance is Measured by the Securities Market Line," Journal of Finance (September 1978), 1051-1069.

15. W. Sharpe, “A Simplified Model for Portfolio Analysis," Management Science (January 1963), 277-293. 